\title{
PRODUÇÃO DE ÁCIDO CÍTRICO POR ASPERGILLUS NIGER: AVALIAÇÃO DE DIFERENTES FONTES DE NITROGÊNIO E DE CONCENTRAÇÁO ḐE SACAROSE
}

\author{
Neivair Sponchiado Pastore ${ }^{I}$ \\ Salah Mahmud Hasan ${ }^{2}$ \\ Denize Aparecida Zempulski
}

\begin{abstract}
Resumo: Neste trabalho objetivou-se a produção de ácido cítrico por fermentação submersa utilizando meio sintético enriquecido com sacarose utilizando o fungo Aspergillus niger além de diferentes fontes de nitrogênio como o sulfato de amônio, a uréia e a peptona. A fermentação foi conduzida em frascos erlenmeyer e em estufa bacteriológica. Através dos resultados obtidos, constatou-se a produção de ácido cítrico em todos os meios fermentados testados. O uso de peptona associado ao uso do sulfato de amônio para o meio sintético de Prescott \& Dunn, apresentou melhor produção (62,9 g/L.dia de ácido cítrico) sob as condições estudadas. Em relação ao tempo para a fermentação, foi constatado que o tempo de $24 \mathrm{~h}$ é o ideal para maior produtividade no processo.
\end{abstract}

Palavras chave: ácido cítrico, fermentação submersa, Aspergillus niger

\begin{abstract}
The aim of this work was the production of citric acid by submerged fermentation in a synthetic medium enriched with sucrose using the fungus Aspergillus niger under different nitrogen resources like ammonium sulfate, urea and peptone. The fermentation was carried out in Erlenmeyer flasks and in bacteriological incubator. It was observed the production of citric acid in all the fermented mediums. The use of peptone associated to the utilization of ammonium sulfate in the Prescott \& Dunn synthetic medium showed higher production (62.9 g/L.day of citric acid) under the studied conditions. It was also concluded that the fermentation time of $24 \mathrm{~h}$ was ideal for the higher process productivity.
\end{abstract}

Keywords: citric acid, submerged fermentation, Aspergillus niger

\section{INTRODUÇÃO}

O ácido cítrico ou citrato de hidrogênio, de nome oficial ácido 2-hidroxi-1,2,3-propanotricarboxílico, é um ácido orgânico fraco, que se pode encontrar nos citrinos. É usado como conservante natural (antioxidante), sendo conhecido também como acidulante INS 330, dando um sabor ácido e refrescante na preparação de alimentos e de bebidas. Em bioquímica, é importante o seu papel como intermediário do ciclo do ácido cítrico, de forma que ocorre no metabolismo de quase todos os seres vivos. O ácido cítrico é obtido na indústria graças à fermentação da sacarose realizada por um micro-organismo chamado Aspergillus Niger.
O processo de obtenção apresenta várias fases como a preparação do substrato de melaço, a fermentação aeróbica da sacarose pelo Aspergillus, a separaçáo do ácido cítrico do substrato por precipitação ao adicionar hidróxido de cálcio, ou cal apagada, para formar citrato de cálcio e, depois, é adicionado ácido sulfúrico para decompor o citrato de cálcio. A eliminação das impurezas é realizada com carvão ativado ou resinas de troca iônica, continuando com a cristalizaçáo do ácido cítrico, secagem ou desidrataçáo e o empacotamento do produto (SOCCOL et al., 2006). A produção de ácido cítrico depende principalmente do poten-

\footnotetext{
${ }^{1}$ Departamento de Bioengenharia da Universidade Federal do Paraná

2 Departamento de Engenharia Química, área Bioengenharia da Universidade Estadual do Oeste do Paraná

${ }^{3}$ Departamento de Engenharia Química, área Bioengenharia da Universidade Estadual do Oeste do Paraná
} 
cial de síntese do micro-organismo utilizado, porém as condiçôes do processo e a composição do meio fermentativo são variáveis importantes que, quando otimizadas, podem promover um acréscimo no rendimento (MILLIS, 1985).

Aproximadamente $70 \%$ do ácido cítrico produzido é utilizado na indústria alimentícia e de bebidas, $12 \%$ na farmacêutica e $18 \%$ é destinado a outros usos industriais (LEONEL \& CEREDA 1995).

Desde 1930, existe a preocupação sobre os mecanismos bioquímicos que provocam a acumulação de ácido cítrico no meio de cultivo com micro-organismos. O ácido cítrico só se acumula de duas maneiras: ou quando vários nutrientes estão presentes em altas concentraçóes (açúcar, acidez, oxigênio) ou quando estão em níveis abaixo do ótimo (íons metálicos, nitrogênio, fosfato). Várias situaçôes bioquímicas parecem cooperar na produtividade em ácido cítrico. Por causa disso, nem sempre a influência de fatores individuais pode ser determinada sem que haja influência sobre outros fatores. Atualmente, o ácido cítrico é quase que exclusivamente obtido através de processos de biossíntese utilizando como agente biológico o fungo imperfeito Aspergillus niger. Dois processos são utilizados na biossíntese deste ácido, o de superfície e o submerso, que se diferenciam essencialmente pelo modo de crescimento do micro-organismo (LEONEL \& CEREDA, 1995). Existem muitos fungos produtores de ácido cítrico: Penicillium citrinum, Mucor piriformis, Ustilina vulgaris, Penicillium luteum, Aspergillus clavatus. São de interesse industrial as espécies que permitem altos rendimentos de produção de ácido cítrico, entre estes os fungos do gênero Aspergillus são muito empregados para este propósito (LIMA et al., 2001).

Para que a obtenção do ácido cítrico seja viável comercialmente, vários fatores devem ser levados em consideração no processo fermentativo, como por exemplo, os constituintes do meio de cultivo, o pH, a aeraçáo, a temperatura e o micro-organismo empregado (KOLICHESKI, 1995). Os fungos filamentosos além de sintetizar o ácido cítrico, também secretam uma grande variedade de enzimas extracelulares como protease, amilase, celulases, lípases entre outras.

O nitrogênio é constituinte essencial do tecido fúngico, já que está presente em todas as moléculas de aminoácidos e conseqüentemente nas proteínas. Tanto os substratos naturais como os substratos sintéticos e semi-sintéticos utilizados no cultivo de fungos deve conter uma fonte de nitrogênio, no entanto observa-se que os fungos apresentam diferenças na habilidade para a utilização das diversas fontes de nitrogênio. Nenhum fungo conhecido fixa nitrogênio atmosférico. Fontes de nitrogênio são requeridas para a síntese de aminoácidos, vitaminas, purinas e pirimidinas dos ácidos nucléicos e para síntese de glicosamina para montagem de quitina (polímero que é o principal componente estrutural do exoesqueleto de invertebrados e da parede celular fungica) (TRABULSI, 2005).

Dependendo da espécie do fungo, o nitrogênio pode ser obtido nas formas de nitrato, nitrito, amônia ou nitrogênio orgânico. A maioria dos fungos usa nitrato que é reduzido a nitrito com mediação da enzima nitrato redutase e depois a amônia. A determinação da fonte de nitrogênio é essencial, pois o nitrogênio está intimamente relacionado ao metabolismo dos micro-organismos. Das várias formas de nitrogênio encontradas na natureza, os micro-organismos assimilam mais facilmente a amônia. Porém, micro-organismos que possuem enzimas nitrato redutase e nitrito redutase apresentam a capacidade de assimilar, respectivamente, nitrato ou nitrito, reduzindo nitrato à nitrito, e nitrito à amônia (PUTZKE, 2002).

Como fonte de nitrogênio são freqüentemente utilizados o sulfato de amônio (o qual costuma provocar reduçáo significativa do $\mathrm{pH}$ e, em alguns casos, fenômenos de inibição pelo sulfato), uréia (a qual permite reduzir problema de controle de $\mathrm{pH}$ ) e peptona (a qual costuma ser bastante dispendiosa, inviabilizando seu uso industrial) (SCHMIDELL, 2001). Após definir qual o micro-organismo e as condiçóes de nutrientes necessárias para o seu desenvolvimento, define-se qual o processo fermentativo a ser utilizado, levando em consideração o tipo de substrato a ser utilizado. Os substratos a serem utilizados podem estar tanto na forma natural como na forma sintética, dependendo do processo que se deseje realizar, da facilidade de se obter a matéria prima ou dos resultados que se desejam obter. Levando isto em consideração, o objetivo deste trabalho foi avaliar a produção de ácido cítrico de Aspergillus niger por fermentaçáo submersa em meio sintético de Prescott \& Dunn suplementado por fontes de ni- 
trogênio (uréia, peptona e sulfato de amônio) e sacarose.

\section{MATERIAIS E MÉTODOS}

\subsection{MICRO-ORGANISMO}

O micro-organismo utilizado neste trabalho foi o fungo Aspergillus niger, cedido pelo laboratório de Bioquímica do Centro de Ciências Biológicas e da Saúde, UNIOESTE - Cascavel. Foi conservado sob refrigeraçáo a $4^{\circ} \mathrm{C}$ em meio inclinado BDA (Batata Dextrose Agar), sendo repicado a cada dois meses. O preparo do inoculo foi feito com $800 \mathrm{~mL}$ de meio BDA inclinado, e incubando o fungo Aspergillus niger por um período de 9 dias a $30^{\circ} \mathrm{C}$. Após, foi feita raspagem dos esporos na superfície com $200 \mathrm{~mL}$ de água estéril e uma gota de Tween 80 . Em seguida, a suspensão de esporos foi filtrada em algodão estéril, a fim de remover o micélio e ágar, e feita a contagem de esporos em câmara de Neubauer de onde se objetivou obter a concentração padrão de $10^{8}$ esporos/ $\mathrm{mL}$ de substrato na fermentação.

\subsection{SUBSTRATO}

O meio sintético utilizado foi o de Prescott \& Dunn (1959), que foi distribuído em erlenmeyers de $250 \mathrm{~mL}$ na proporção de $80 \mathrm{~mL}$ por frasco e esterilizados a $121^{\circ} \mathrm{C}$ por 15 minutos. $\mathrm{O}$ meio sintético utilizado no experimento para a fermentação submersa é constituído de carboidratos e sais orgânicos, contendo sacarose $(\mathrm{g} / \mathrm{L}), 50$; $\mathrm{NH}_{4} \mathrm{NO}_{3}, 1 ; \mathrm{KH}_{2} \mathrm{PO}_{4}, 1 ; \mathrm{MgSO}_{4} .7 \mathrm{H}_{2} \mathrm{O}, 0,23$.

\subsection{PRODUÇÃO DE ÁCIDO CÍTRICO POR FERMENTAÇÃO SUBMERSA}

Após a esterilização, o meio foi resfriado, inoculado com $1,5 \mathrm{~mL}$ da suspensão com $10^{8}$ esporos $/ \mathrm{mL}$ e incubado a $30^{\circ} \mathrm{C}$ e $100 \mathrm{rpm}$ em shaker, por 6 dias. A coleta de amostras ocorreu a cada 24h sendo utilizadas para análises de ácido cítrico, $\mathrm{pH}$ e açúcar redutor. Os ensaios de fermentação submersa (FSm) foram conduzidos em frascos erlenmeyer de $250 \mathrm{~mL}$. O extrato bruto coletado foi filtrado e centrifugado $(10.000 \mathrm{~g}$ por $5 \mathrm{~min})$, para remoção dos sólidos suspensos e, posteriormente, acondicionado em freezer para serem analisados.

\subsection{MÉTODOS ANALÍTICOS}

A determinação de ácido cítrico foi realizada seguindo o método de Saffran \& Denstedt (1948), neste método pequenas quantidades de ácido cítrico são determinadas baseando-se na formação da cor amarela na presença de ácido tricloroacético (TCA), anidrido acético e piridina. Para a curva padrão foi utilizada uma solução de ácido cítrico dissolvendo $4 \mathrm{~g}$ de ácido cítrico em $100 \mathrm{~mL}$ de TCA a $15 \%$.

O método de determinação da concentração de açúcar redutor usado neste trabalho foi baseado no método proposto por Miller (1959), o qual utiliza o reagente DNS (ácido 3,5-dinitrosalicílico) e possui sensibilidade na faixa de 0,1 a 1,0 $\mathrm{g} / \mathrm{L}$ de açúcar redutor expresso como glicose. A curva padrão de glicose foi construída nas mesmas condições para a determinação de ácido cítrico, utilizando sacarose como padrão.

O fluxograma (Figura1) mostra de maneira simplificada as principais etapas realizadas neste trabalho.

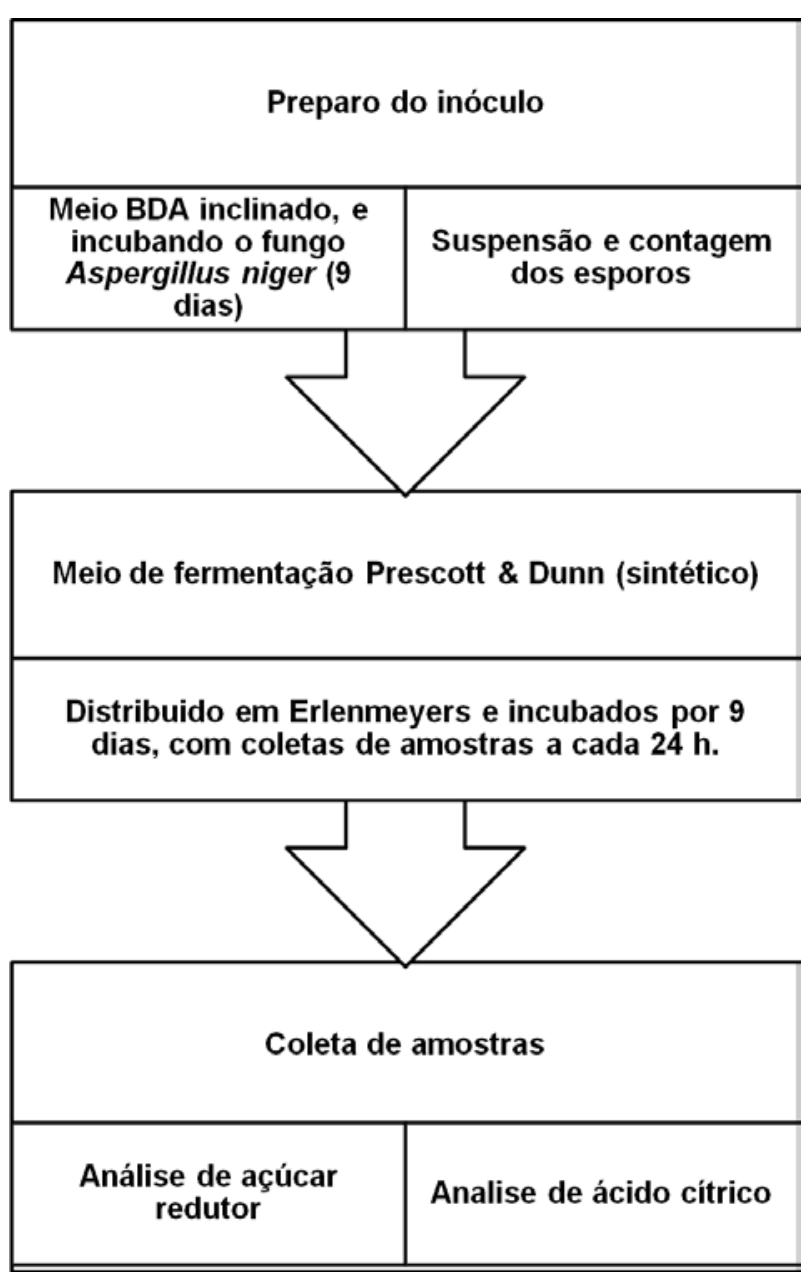

Figura 1. Fluxograma de trabalho 


\subsection{PLANEJAMENTO EXPERIMEN-TAL}

Para a avaliação do processo de produção de ácido cítrico, executou-se o planejamento experimental fatorial $2^{4}$ com seis repetiçóes no ponto central, totalizando 22 ensaios. As variáveis estudadas foram a concentraçáo de sacarose e a concentração de diferentes fontes de nitrogênio (uréia, peptona e sulfato de amônio), cujos níveis estão apresentados na Tabela 1. O meio sintético possui em sua composiçáo $5 \%$ de sacarose, sendo esta a concentraçáo mínima inicial de sacarose nos meios utilizados neste trabalho, correspondendo ao nível -1 apresentado na Tabela 1. Nesta tabela os níveis dos fatores referem-se a suplementação dos ensaios, e não a concentração inicial nos meios.

Tabela 1: Níveis dos fatores utilizados no planejamento fatorial $2^{4}$.

\begin{tabular}{cccc}
\hline \multirow{2}{*}{ Variável } & \multicolumn{3}{c}{ Nível } \\
\cline { 2 - 4 } & -1 & 0 & 1 \\
\hline Uréia $(\mathrm{g} / \mathrm{L})$ & 0 & 2,5 & 5 \\
Peptona $(\mathrm{g} / \mathrm{L})$ & 0 & 2,5 & 5 \\
S. de Amônio $(\mathrm{g} / \mathrm{L})$ & 0 & 2,5 & 5 \\
Sacarose $(\mathrm{g} / \mathrm{L})$ & 0 & 50 & 100 \\
\hline
\end{tabular}

Os resultados obtidos na produção de ácido cítrico foram analisados no programa Statistica ${ }^{\mathrm{TM}}$ (v. 8.0) onde foi realizada uma estimativa dos efeitos das variáveis sobre a resposta analisada. Os experimentos foram monitorados através da análise da produção de ácido cítrico $(\mathrm{g} / \mathrm{L})$, variação de $\mathrm{pH}$ e concentração de açúcares redutores $(\mathrm{g} / \mathrm{L})$. A análise do planejamento experimental do tipo $2^{4}$ gera valores de coeficientes $\beta$ para um modelo matemático linear conforme a equaçáo (1),

$$
\begin{aligned}
& y=\beta_{0}+\beta_{1} \cdot x_{1}+\beta_{2} \cdot x_{2}+\beta_{3} \cdot x_{3}+\beta_{4} \cdot x_{4}+ \\
& \beta_{2} \cdot x_{1} \cdot x_{2}+\beta_{\mathfrak{B}} \cdot x_{1} \cdot x_{3}+\beta_{4} \cdot x_{1} \cdot x_{4}+ \\
& \beta_{3} \cdot x_{2} \cdot x_{3}+\beta_{3} \cdot x_{2} \cdot x_{4}+\beta_{3} \cdot x_{3} \cdot x_{4} \ldots \ldots . .(1)
\end{aligned}
$$

onde y é a variável resposta e corresponde a produtividade de ácido cítrico em $24 \mathrm{~h}$ de fermentação, $\mathrm{x}_{1}, \mathrm{x}_{2}, \mathrm{x}_{3}$ e $\mathrm{x}_{4}$ são as variáveis estudadas correspondentes aos níveis das concentraçôes de uréia, peptona, sulfato de amônio e sacarose, respectivamente, os demais parâmetros da equação referem- -se a interação de duas variáveis e os diferentes $\beta$ são os coeficientes calculados para cada termo da equação, sendo $\beta_{0}$ o termo independente o qual corresponde ao intercepto da reta no eixo y.

\section{RESULTADOS E DISCUSSÃO}

Visando avaliar a produção de ácido cítrico com A. niger fez-se um estudo com o meio sintético de Prescott \& Dunn variando-se a concentraçáo de diferentes fontes de nitrogênio (uréia, peptona e sulfato de amônio) além da concentração da fonte de carbono (sacarose). Para tanto foi utilizada a matriz de planejamento fatorial completo $2^{4} \mathrm{com}$ sextuplicata no ponto central, conforme Tabela 2 .

Assim, para cada um dos 22 ensaios do planejamento foram coletadas amostras ao longo do tempo, sendo uma amostra a cada 24 h, durante 6 dias, para analisar e verificar o comportamento da produçáo de ácido cítrico, do $\mathrm{pH}$ e do consumo de açúcar redutor. Posteriormente, foi realizada a análise estatística considerando-se o melhor tempo para a produção de ácido cítrico.

Verificou-se, mediante análise das curvas cinéticas dos 22 ensaios, que o tempo de fermentação de $24 \mathrm{~h}$ apresentava os maiores níveis de produtividade para o ácido cítrico. Assim, a Tabela 2 apresenta, para cada ensaio o resultado de produtividade em 24 h de produçáo. Uma análise inicial da tabela indica que o ensaio número 7 apresenta maior resultado de produtividade $(62,9 \mathrm{~g} / \mathrm{L}$.dia) de ácido cítrico, correspondente aos níveis inferiores para a uréia e sacarose e aos níveis superiores de peptona e sulfato de amônio.

Os piores resultados foram obtidos no nível central (ensaios 17 à 22), com baixos valores de produtividade. Normalmente, no ponto central são fixados os níveis onde se espera obter os melhores resultados para então se fazer uma análise do processo nos demais níveis. Assim, os resultados obtidos indicam que o ponto central está situado, ou próximo a uma região de mínimo, onde qualquer variação, para menos ou para mais nos níveis dos quatro fatores resulta no acréscimo da produtividade em ácido cítrico. Apesar, dos valores inferiores de produção de ácido cítrico, verifica-se nas repetiçóes no nível zero que houve um alto grau de reprodutibilidade dos ensaios, o que diminui significativamente a incerteza na análise estatística.

Através de análise estatística preliminar verificou-se que o modelo linear (equação 1) resultan- 
Tabela 2: Matriz do planejamento fatorial experimental $2^{4}$ com resultados de produtividade de ácido cítrico (AC) para o tempo de $24 \mathrm{~h}$ de fermentação.

\begin{tabular}{|c|c|c|c|c|c|}
\hline Ensaio & Uréia $\left(\mathrm{x}_{1}\right)$ & Peptona $\left(\mathrm{x}_{2}\right)$ & $\begin{array}{c}\text { Sulfato de } \\
\text { Amônio }\left(\mathrm{x}_{3}\right)\end{array}$ & Sacarose $\left(\mathrm{x}_{4}\right)$ & $\begin{array}{c}\text { Produtividade AC (g/L.dia) } \\
\text { em 24h (y) }\end{array}$ \\
\hline 1 & -1 & -1 & -1 & -1 & 57,2 \\
\hline 2 & 1 & -1 & -1 & -1 & 58,3 \\
\hline 3 & -1 & 1 & -1 & -1 & 56,3 \\
\hline 4 & 1 & 1 & -1 & -1 & 45,9 \\
\hline 5 & -1 & -1 & 1 & -1 & 61,4 \\
\hline 6 & 1 & -1 & 1 & -1 & 58,4 \\
\hline 7 & -1 & 1 & 1 & -1 & 62,9 \\
\hline 8 & 1 & 1 & 1 & -1 & 56,4 \\
\hline 9 & -1 & -1 & -1 & 1 & 60,1 \\
\hline 10 & 1 & -1 & -1 & 1 & 57,4 \\
\hline 11 & -1 & 1 & -1 & 1 & 57,7 \\
\hline 12 & 1 & 1 & -1 & 1 & 58,3 \\
\hline 13 & -1 & -1 & 1 & 1 & 67,5 \\
\hline 14 & 1 & -1 & 1 & 1 & 60,3 \\
\hline 15 & -1 & 1 & 1 & 1 & 80,5 \\
\hline 16 & 1 & 1 & 1 & 1 & 80,0 \\
\hline 17 & 0 & 0 & 0 & 0 & 8,1 \\
\hline 18 & 0 & 0 & 0 & 0 & 8,1 \\
\hline 19 & 0 & 0 & 0 & 0 & 8,1 \\
\hline 20 & 0 & 0 & 0 & 0 & 8,8 \\
\hline 21 & 0 & 0 & 0 & 0 & 0 \\
\hline 22 & 0 & 0 & 0 & 0 & \\
\hline
\end{tabular}

te do tipo de planejamento fatorial utilizado não apresentou ajuste aos resultados experimentais de produtividade em ácido cítrico, o que implica na necessidade da inserção de um ou mais termos quadráticos na equação, gerando assim um modelo não linear. Portanto, a Tabela 3 apresenta os valores dos coeficientes calculados para o modelo linear (equação 1) originalmente proposto, acrescido do termo de "curvatura" necessário para a geração de um modelo quadrático. $\mathrm{O}$ baixo $\mathrm{p}$-valor indica que todos os parâmetros são significativos no modelo (incluindo a curvatura) e influenciam no processo ( $\mathrm{p}$-valor $<\alpha)$, considerando-se o nível de significância de $5 \%(\alpha=0,05)$. A análise de variância dos dados (Tabela 4), por sua vez indica que um modelo linear náo é adequado para representar o comportamento do processo, ou seja, originalmente um modelo quadrático ajustaria melhor os dados experimentais obtidos. Isso fica mais evidenciado pelo termo relativo a curvatura (Tabela 3) determinada como parâmetro a ser inserido no modelo. Observa-se o elevado grau de influência da curvatura no modelo pelo p-valor que resultou em zero.

A análise de variância, ANOVA, (Tabela 4) foi feita considerando no resíduo a influência da falta de ajuste do modelo, a qual ficou fortemente evidenciada pelo p-valor igual a zero, indicando a real necessidade da inserçáo da curvatura no modelo através de um ou mais termos quadráticos. $\mathrm{O}$ valor da média quadrática (MQ) para o erro puro está relacionada a variância global do processo em termos de erros sistemáticos e aleatórios. Dessa forma, seu baixo valor obtido indica a boa reprodutibilidade do processo, o que foi corroborado pelos ensaios em sextuplicata no planejamento experimental. 
Tabela 3: Coeficientes do modelo linear gerado pelo planejamento $2^{4}(\alpha=0,05)$

\begin{tabular}{|c|c|c|c|}
\hline Parâmetro & Coeficiente & Erro padrão do coeficiente & p-valor \\
\hline Intercepto & $\beta_{0}=56,1625$ & 0,030619 & 0,000000 \\
\hline Curvatura & $-48,1125$ & 0,058630 & 0,000000 \\
\hline UR & $\beta_{1}=-1,7875$ & 0,030619 & 0,000000 \\
\hline PEP & $\beta_{2}=-1,4125$ & 0,030619 & 0,000000 \\
\hline SAM & $\beta_{3}=-0,2375$ & 0,030619 & 0,000570 \\
\hline SAC & $\beta_{4}=-0,9375$ & 0,030619 & 0,000001 \\
\hline Interação $x 1 . x 2$ & $\beta_{12}=-2,8125$ & 0,030619 & 0,000000 \\
\hline Interação x1.x3 & $\beta_{13}=-0,3625$ & 0,030619 & 0,000076 \\
\hline Interação x1.x4 & $\beta_{14}=0,5625$ & 0,030619 & 0,000009 \\
\hline Interação $\times 2.3$ & $\beta_{23}=0,4375$ & 0,030619 & 0,000030 \\
\hline Interação $\times 2 . x 4$ & $\beta_{24}=0,3125$ & 0,030619 & 0,000155 \\
\hline Interação $\times 3 . x 4$ & $\beta_{34}=-2,9125$ & 0,030619 & 0,000000 \\
\hline
\end{tabular}

$\mathrm{R}^{2}=0,98$

Tabela 4: Análise de variância do planejamento fatorial $2^{4}(\alpha=0,05)$

\begin{tabular}{|c|c|c|c|c|c|}
\hline Fonte de variação & SQ & GL & MQ & F & p-valor \\
\hline Modelo com curvatura & 10473,09 & 11 & 952,10 & 44,70 & - \\
\hline Falta de ajuste (a) & 212,95 & 5 & 42,59 & 4259 & 0,00000 \\
\hline Erro puro (b) & 0,07 & 5 & 0,01 & & \\
\hline Resíduo (a+b) & 213,02 & 10 & 21,30 & & \\
\hline Total & 10686,11 & 21 & & & \\
\hline
\end{tabular}

$\mathrm{SQ}=$ soma quadrática; $\mathrm{GL}$ = graus de liberdade; $\mathrm{MQ}=$ média quadrática; $\mathrm{F}$ = estatística $\mathrm{F}$

Os valores negativos dos coeficientes do modelo (Tabela 3) indicam que para alcançar-se maiores produtividades de ácido cítrico deve-se procurar trabalhar com níveis mais baixos de concentração dos quatro nutrientes (entre 0 e -1). Assim, pretende-se, numa etapa posterior, implementar um novo delineamento do tipo composto central rotacional (DCCR) para viabilizar um ajuste não linear às variáveis estudadas. No DCCR as 4 variáveis seriam avaliadas nos níveis $-2,-1,0,+1$ e +2 .

A diferença entre da utilização de diferentes meios já havia sido observada por Adham (2002), que utilizou meio sintético e meio contendo melaço de beterraba em diferentes concentraçôes de óleos vegetais e diferentes tipos de fermentaçôes, neste caso, o autor chegou a conclusão que o fungo apresenta diferentes respostas para os íons metálicos e minerais presentes nos meios de fermentação.

Foram feitas as curvas cinéticas de produção de ácido cítrico, consumo de açúcar redutor para o ensaio número 7 do planejamento fatorial (Figura 2).

Qualquer aumento ou diminuição na concentração de nitrogênio no meio de fermentação faz com que ocorram oscilaçôes na produção de ácido cítrico (SIKANDER et al., 2004). Seguindo a observação dos autores, pode-se verificar na Figura 1 a ocorrência desta oscilaçáo, sendo que a maior concentração de ácido cítrico foi de 62,9 $\mathrm{g} / \mathrm{L}$ para o primeiro dia. No meio de fermentaçáo do ensaio 7, utilizou-se a peptona e o sulfato de amônio como fontes de nitrogênio o que suporia 
uma rápida metabolização do sulfato de amônio pelo fungo, produzindo acido cítrico.

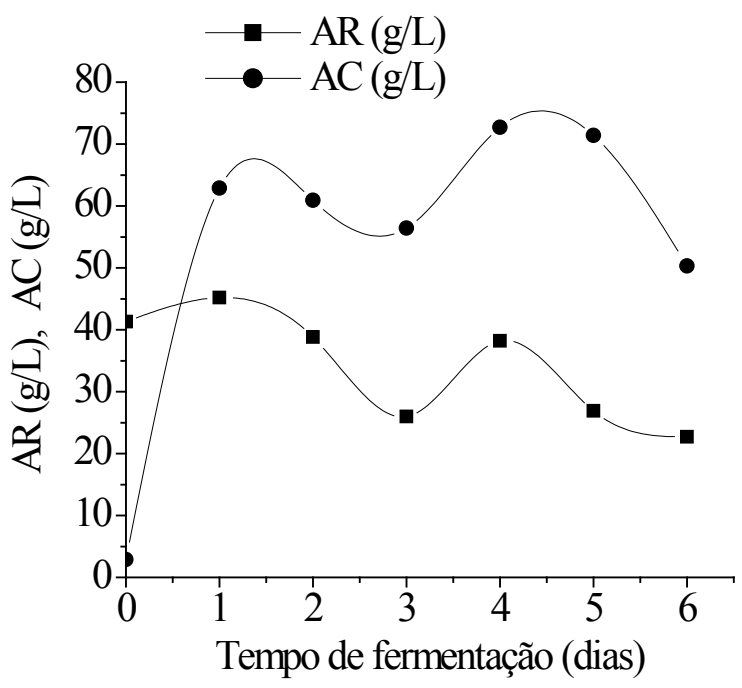

Figura 2. Perfis cinéticos de concentraçáo do ácido cítrico $(\mathrm{AC})$ e açúcar redutor $(\mathrm{AR})$ obtidos para o ensaio $\mathrm{n}^{\mathrm{o}} 7$ do planejamento fatorial $2^{4}$.

Entretanto como o meio também possui peptona como fonte de nitrogênio, e a assimilação desta é lenta devido a necessidade da decomposição da mesma para a liberação do nitrogênio, conseqüentemente durante o processo de decomposição também pode ocorrer uma degradação do ácido cítrico já produzido. Neste caso pode-se observar que no intervalo de tempo entre o segundo e o terceiro dia de fermentação o fungo poderia voltar a apresentar uma nova fase de germinação, isso porque peptona é fonte de nitrogênio orgânico e contem algumas vitaminas e/ou carboidratos, dependendo do material protéico digerido para a sua produção. Isso faz com que ocorra um aumento da biomassa, com diminuição ou consumo dos açúcares redutores presentes no meio e posteriormente voltando a produzir o ácido cítrico.

As oscilaçóes observadas na produção de ácido cítrico durante a fermentaçáo podem ocorrer também em funçáo da produçáo de dióxido de carbono, que apesar deste parâmetro não ser analisado neste experimento, coincide com os resultados obtidos por Priede \& Thomas (1999), que também observaram estas oscilações ao estudarem a relação entre a morfologia e a produção de ácido cítrico por Aspergillus niger em fermentação submersa utilizando meio sintético.
Com base nos resultados obtidos neste trabalho pode-se afirmar que o $\mathrm{pH}$ do meio de fermentação sintético de Prescott \& Dunn, que é inicialmente na faixa entre 4 e 6 (pelo fato de não estar tamponado), apresentou diminuiçáo significativa (Figura 3), sendo este um parâmetro importante que foi observado no decorrer do tempo, pois indica que durante a fermentaçáo do meio, ocorreu a formação de ácidos orgânicos, entre eles o ácido cítrico, contribuindo para seu abaixamento.

Fontes de carboidrato também são necessárias para a produção de ácido cítrico, sendo que a presença de carboidrato prontamente metabolizável é essencial para uma boa produção de ácido cítrico. A maltose, sacarose, manose, glicose e frutose são os açúcares mais apropriados para a produção de ácido. Neste trabalho foi utilizado a sacarose como fonte de carboidrato, entretanto o meio que apresentou melhor resultados (ensaio 7) não foi suplementado com a sacarose, utilizando apenas a concentração inicial de $50 \mathrm{~g} / \mathrm{L}$ no meio sintético (própria do meio). Observa-se que a variação temporal do acúmulo do ácido cítrico corresponde exatamente com a diminuição do $\mathrm{pH}$ assim que se inicia a produção do ácido cítrico, conforme observado na Figura 1. Bonatelli Jr. et al. (1982), realizando fermentação em meio sintético Prescott \& Dunn, por um período de 7 dias, obtiveram uma produção máxima de $92 \mathrm{~g} / \mathrm{L}$ a partir de uma cepa de fungo Aspergillus niger mutante, após $48 \mathrm{~h}$ de incubação.

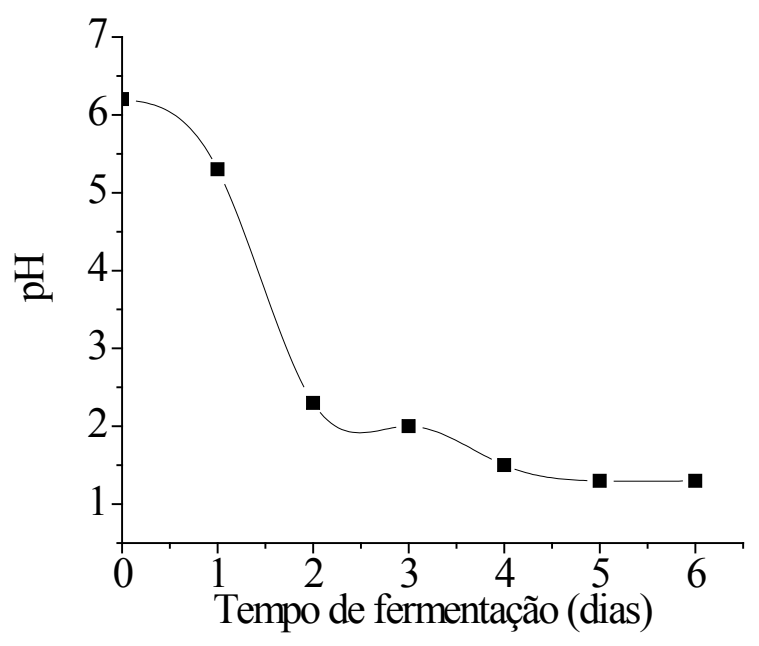

Figura 3. Variação do $\mathrm{pH}$ com o tempo de fermentaçáo obtida para o ensaio $n^{\circ} 7$ do planejamento fatorial $2^{4}$. 
Dorouneh et al (2009), obtiveram uma produtividade de 13,4 g/L.dia em fermentação submersa, após um período de 10 dias, utilizando o meio sintético, entretanto ao utilizar um meio enriquecido com melaço de cana de açúcar obteve uma produtividade de $12 \mathrm{~g} / \mathrm{L}$.dia após 10 dias.

Um fator importante que deve ser levado em consideração durante o período de fermentação é o $\mathrm{pH}$, no ensaio 7 , observa-se um $\mathrm{pH}$ inicial de 6,2 e final de 1,3. Segundo Papagianni (2007), valores de $\mathrm{pH}$ baixo inibem a produção de ácidos orgânicos indesejáveis (ácido glucônico e ácido oxálico), tornando a recuperação de ácido cítrico mais simples a partir do meio de fermentaçáo. Sabe-se também que nenhum fungo conhecido consegue fixar nitrogênio atmosférico, desta forma, fontes de nitrogênio são requeridas para a síntese de aminoácidos, vitaminas, purinas e pirimidinas dos ácidos nucléicos e para síntese de glicosamina para montagem de quitina (principal componente da parede celular do fungo). A fermentação cítrica submersa requer também uma concentração de fonte de nitrogênio de 0,1 a 0,4 g/L. Em elevada quantidade, este composto propicia o crescimento fúngico e o consumo de substrato, diminuindo o acúmulo de ácido cítrico (SOCCOL et al., 2006). Os compostos de sais de amônio (sulfato de amônio e nitrato de amônio) são os mais empregados, pois ao serem consumidos, diminuem o $\mathrm{pH}$ do meio, o que é essencial para obtenção de ácido cítrico (YIGITOGLU, 1992). Isso justifica a redução de $\mathrm{pH}$ observada no ensaio 7.

Dependendo da espécie do fungo, o nitrogênio pode ser obtido nas formas de nitrato, nitrito, amônia ou nitrogênio orgânico. A maioria dos fungos usa nitrato que é reduzido a nitrito com mediação da enzima nitrato redutase e depois a amônia. Esta é a forma na qual ocorre a captação de amônia no meio de fermentação no inicio da germinaçáo dos esporos do fungo e provocam liberação de prótons o que contribui para a redução do $\mathrm{pH}$ a níveis adequados para que ocorra a total germinação destes esporos. Se durante essa fase ocorrer um aumento de $\mathrm{pH}$ acima de 4,5 a produção de ácido cítrico pode ser reduzida em até 80\% (PAPAGIANNI, 1995).

$\mathrm{O}$ controle de $\mathrm{pH}$ também pode ser crítico nos processos de fermentação (NAGEL et al., 1999), pois como conseqüência da degradação dos açúcares ou matéria orgânica presente no meio, ocorre a formaçáo de ácidos orgânicos que baixam o pH, assim como o consumo de sais de amônio. Por outro lado, se ácidos orgânicos presentes no substrato sáo assimilados, o $\mathrm{pH}$ aumenta, assim como a hidrólise de uréia resulta na alcalinização do meio (RAIMBAULT, 1998).

A amônia também é bastante utilizada como nutriente pelos fungos, porém, quando o meio é básico, ela se torna tóxica para estes micro-organismos e o Aspergillus niger necessita de fonte de nitrogênio para a produção de ácido cítrico (HAQ et al., 2005). De acordo com Esposito \& Azevedo (2004), os fungos podem utilizar amônia por difusão simples através da membrana celular, entretanto os íons amônio presentes não atravessam a parede celular. Porém, Roukas \& Harvey (1988) explicaram que no interior da célula, nitrato é convertido a nitrito e este ao íon amônio que então é utilizado pelo fungo. Para que isto ocorra, o pH ótimo deve estar entre 4 e 6 e o íon amônio não será metabolizado intracelularmente se o $\mathrm{pH}$ for inferior a 4 (GRIFFIN, 1994).

As mudanças de $\mathrm{pH}$, ao longo do cultivo, dependem principalmente do micro-organismo e do substrato e para amenizar o efeito de uma variação brusca do $\mathrm{pH}$ a adição de sais de amônio ou uréia também pode ser usada. De um modo geral, na fermentação submersa os valores iniciais de $\mathrm{pH}$ são baixos, favorecendo o crescimento de fungos e leveduras e dificultando o crescimento de bactérias (DEL BIANCHI et al., 2001). Porém, não há consenso na literatura sobre um $\mathrm{pH}$ inicial ótimo para o acúmulo de ácido cítrico. Yigitoglu et al. (1992), indicam que um $\mathrm{pH}$ de 2,5 seria o ideal para a concentração do produto. Papagianni (1995) afirma que um $\mathrm{pH}$ de 4,5 durante a fase de produção reduz o rendimento do ácido cítrico, no entanto para que haja o desenvolvimento de esporos é necessário um $\mathrm{pH}$ em torno de 5,5.

Ainda que o $\mathrm{pH}$ mais favorável ao desenvolvimento dos fungos esteja entre 5, 6 e 7 , a maioria dos fungos toleram amplas variaçóes de $\mathrm{pH}$. Os fungos filamentosos podem crescer na faixa entre 1,5 e 11, entretanto algumas leveduras náo toleram $\mathrm{pH}$ alcalino. Os meios com $\mathrm{pH}$ entre 5 e 6, com elevadas concentraçóes de açúcar e alta pressão osmótica, tais como geléias, favorecem o desenvolvimento dos fungos nas porçôes que estiverem em contato com o ar. Desta forma, neste trabalho utilizou-se um $\mathrm{pH}$ inicial na faixa entre 5 e 7 , sendo que os meios não foram tamponados, assim pode-se observar uma variação natural no 
valor de $\mathrm{pH}$ durante o período de fermentação, embora os constituintes normais, como a peptona e os aminoácidos, presentes nos meios de fermentação, possam funcionar como tampóes, em virtude de sua própria natureza.

Foi observado neste trabalho um decaimento no $\mathrm{pH}$ nos ensaios $7,9,10,11,12,13,14 \mathrm{e}$ 16, isto ocorre, segundo Lehninger et al. (1995), devido à produção de algumas moléculas ácidas pelo fungo Aspergillus niger quando cultivado na presença de meios contendo fontes de nitrogênio. Com exceção do ensaio 7 os demais ensaios foram suplementados com sacarose, o decaimento de $\mathrm{pH}$ pode estar relacionado com a decomposiçáo da matéria orgânica presente nos meios. Outro fator que pode influenciar no decaimento do $\mathrm{pH}$ é a presença da peptona que também pode ser utilizada como matéria orgânica, uma vez que o meio possui sulfato de amônio, como fonte de nitrogênio, favorecendo o desenvolvimento fungico e o acúmulo do ácido cítrico. Os demais meios não foram suplementados com sacarose apenas com as fontes de nitrogênio inorgânico (uréia e sulfato de amônio) e orgânico (peptona), nos meios 1, $5,6,17,18,19,20,21$ e 22 o pH manteve-se estável, como citado anteriormente a variação do $\mathrm{pH}$ não ocorre devido a presença de alguns ácido orgânicos e a hidrólise da uréia presente no meio de fermentação inclusive podem torná-lo alcalino como ocorreu nos ensaios 2, 4, 8 e 15.

Outro fator analisado é o consumo de açúcar redutor presente no meio fermentativo. Em geral, apenas os açúcares que são assimilados rapidamente por fungos são utilizados como fonte de carbono na fermentação cítrica (sacarose, frutose, glicose) (YIGITOGLU, 1992). Segundo Kubicek \& Rohr (1986), a principal fonte de carbono empregada é a sacarose, seja na forma pura ou na forma presente em melaços de cana-de-açúcar ou beterraba.

No ensaio 7 a concentração de açúcar redutor inicial foi de 41,3 g/L e final de 22,7 g/L. A concentração e o tipo de fonte de carbono são importantes para o acúmulo de ácido cítrico. Em fermentação submersa a faixa ótima de concentração de sacarose é 10 a 14\%, sendo que abaixo de 2,5\% não há produção de ácido cítrico (XU et al., 1989). Segundo Penna (2001), as baixas concentrações de açúcares facilitam o acúmulo de ácido oxálico, e, conseqüentemente, diminuem a produçáo de ácido cítrico. $\mathrm{O}$ meio sintético pos- sui em sua composição $5 \%$ de sacarose, sendo esta a concentração mínima inicial de sacarose nos meios utilizados neste trabalho, correspondendo ao nível -1 apresentado anteriormente na Tabela 1. Nesta tabela os níveis dos fatores referem-se a suplementação dos ensaios, e não a concentração inicial nos meios.

\section{CONCLUSÁO}

Foi possível observar neste trabalho que a associação de uma ou mais fontes de nitrogênio ao meio de cultivo proporciona maiores rendimentos, sendo que a adição de peptona associada ao sulfato de amônio resultou, no tempo de fermentação de 24 h, uma maior produtividade de ácido cítrico $(62,9$ g/L.dia). O pH em que se obteve o maior rendimento foi o de 5,3 sem que se houvesse utilizado qualquer tipo de correção no meio de fermentação.

Com relação à sacarose pode-se afirmar que com concentraçóes de $50 \mathrm{~g} / \mathrm{L}$ no meio de fermentação (composição original do meio sintético de Prescott \& Dunn) obtém-se valores de acúmulo de ácido cítrico expressivos.

Como o ácido cítrico possui uma gama de utilizaçóes e o mercado consumidor é crescente, a busca de fontes alternativas e de baixo custo para a sua produção torna-se relevante, pois o ácido cítrico compete diretamente no mercado de acidulantes com o ácido lático, fumárico e forfórico.

Para a melhor quantificação e qualificação do ácido cítrico e do açúcar redutor, em trabalho futuro, serão feitas análises de cromatografia líquida e gasosa e desta forma definir qual o método de purificaçáo mais adequado e qual o uso final deste ácido cítrico.

\section{REFERÊNCIAS BIBLIOGRÁFICAS}

Adham, N.Z. Attempts at improving citric acid fermentation by Aspergillus niger in beet-molasses medium. Bioresource Technology, v.84, p.97100, 2002.

Bonatelli Jr., R., Azevedo, J.L., Calent, G.U. Citric acid production by Aspergillus Niger mutants, Revista Brasileira de Genética, v.3, p.483-492, 1982.

Del Bianchi, V.L., Moraes, I.O., Capalbo, D.M.F. Fermentação em Estado Sólido. In: Schmidell, W. 
et al. Biotecnologia Indutrial. São Paulo: Edgard Blücher, 2001.

Dorouneh, E., Alavi, A, Vosoughi, M., Arjmand, M., Seifkordi, A., Rajabi, R. Citric acid production: Surface culture versus submerged culture. African Journal of Microbiology Research v.3, n.9, p. 541-545, 2009.

Esposito, E., Azevedo, J. L. Fungos: uma introdução à biologia, bioquímica e biotecnologia. Caxias do Sul: Editora da Universidade de Caxias do Sul, 2004.

Griffin, D.H. Fungal physiology. 2. ed., New York: Wiley-Liss, 1994.

Haq, I.U., ALI, S., Qadeer, M.S., Iqbal, J. Effect of copperions on mould morfhology and citric acid productivity by $A$. Niger using molasses based media. Process Biochemistry, v.37, 2005.

Kolicheski, M.B. Produção de Ácido Cítrico por Fermentação no Estado Solido utilizando como substrato Bagaço de Mandioca. Curitiba, 2005, 137 p. Dissertação (Mestrado), UFPR.

Kubicek, C.P., Rohr, M. Citric acid fermentation. CRC Critical Reviews in Biotechnology, v.3, Boca Raton, 1986.

Lehninger, A.L. Princípios de Bioquímica, 2. ed. São Paulo:Sarvier, 1995.

Leonel, M., Cereda, M.P. Manipueira como substrato na biossíntese de ácido cítrico por Aspergillus niger. Scientia Agricola, v.52, n.2, 1995.

Lima, U.A., Aquarone, E., Borzani, W., Schimidell, W. Biotecnologia Industrial: Processos Fermentativos e Enzimaticos. São Paulo: Editora Edgard Blucher Ltda., v 3, 2001.

Miller, G.L. Use of dinitrosalicylic acid reagent for determination of reducing sugars. Analytical Chemistry, v.31, p.426-428, 1959.

Millis, N.F. The organims of biotechnology. In: Moo-Young M. Comprehensive Biotechnology, Oxford:Pergamon, v.1, 1985.
Nagel, F.J., Oostra, J., Tramper, J., Rinzema, A. Improved model system for solid-substrate fermentation: effects of $\mathrm{pH}$, nutrients and buffer on fungal growth rate. Process Biochemistry, v.35, p.69-75, 1999.

Papagianni, M. Advances in citric acid fermentation by Aspergillus niger: biochemical aspects, membrane transport and modeling. Biotechnology Advances, v.25, p.244-263, 2007.

Papagianni M. Morphology and citric acid production of Aspergillus niger in submerged culture. $\mathrm{PhD}$ Thesis, University of Strathclyde, England, 1995.

Penna, T.C.V. Produção de ácidos. In: Lima, U.A., Aquarone, E., Borzani, W.,Schidell, W. Biotecnologia Industrial. São Paulo: Edgard Blucher, 2001, v.3, p. 45-50.

Prescott, S.C., Dunn, C.G. Industrial microbiology. 3.ed., New York:Mc Graw-Hill Book, 1959.

Priede, M.A., Thomas, C.R. Relationship between morphology and citric acid production in submerged Aspergillus niger fermentations. Biochemical Engineering Journal, v.3, p. 121-129, 1999.

Putzke, J., Putzke, M.T.L. Os Reinos dos Fungos. 3.ed., v.1. Santa Cruz do Sul: EDUNISC, 2002.

Raimbault, M. General and microbial aspects of solid substrate fermentation. Eletronic Journal of Biotechnology, 1998.

Roukas, T., Harvey, L. The effect of $\mathrm{pH}$ on production of citric and gluconic acid from beet molasses using continuous culture. Biotechnology Letters, 1988.

Schmidell, W. et al. Biotecnologia Industrial. 1.ed., São Paulo:Editora Edgard Blucher, v.2, 2001.

Sikander, A. Studies on the submerged fermentation of citric acid by Aspergillus niger in stirred fermentor. $\mathrm{PhD}$ thesis, University of the Punjab, Lahore. Paquistão, 2004. 
Soccol, C.R., Vandenberghe, L.P.S., Rodrigues, C., Pandey, A. New perspectives for citric acid production and application. Food Technology, v.44, p. 141-149, 2006.

Trabulsi, L.R. Microbiologia. 4.ed., Rio de Janeiro: Editora Atheneu, 2005.
Xu, D.B., Madrid, C.P., Röhr, M., Kubicek, C.P. The influence of type and concentration of the carbon source on production of citric acid by Aspergillus niger. Applied Microbiology and Biotechnology, v.30, p. 553-561, 1989.

Yigitoglu, M. Production of citric acid by fungi. Journal of Islamic Academy of Sciences. 5, 1992. 